\title{
Adjuvant therapy in patients with rectal adenocarcinoma treated with neoadjuvant chemoradiotherapy and radical resection in pathological stages I-III
}

\author{
Leonardo S. Lino-Silva ${ }^{1 \wedge}$, César Zepeda-Najar ${ }^{2}$, Rosa A. Salcedo-Hernández $^{3} \wedge$ \\ ${ }^{1}$ Surgical Pathology, Instituto Nacional de Cancerología, Tlalpan, Mexico City, Mexico; ${ }^{2}$ Surgical Oncology, Hospital Angeles Tijuana, Tijuana, Baja \\ California Norte, Mexico; ${ }^{3}$ Surgical Oncology, Instituto Nacional de Cancerología, Tlalpan, Mexico City, Mexico \\ Correspondence to: Leonardo S. Lino-Silva, MD, MSc, MEd. Anatomic pathology professor, Gastrointestinal Pathology Division and Melanoma \\ Division, Instituto Nacional de Cancerología de México (Mexico's National Cancer Institute), Av. San Fernando \# 22, Sección XVI, Tlalpan, Mexico \\ City, CP 14080, Mexico. Email: saul.lino.sil@gmail.com. \\ Provenance and Peer Review: This article was a free submission to the journal. The article did not undergo external peer review. \\ Response to: Zhang H, Huang Y, Sun G, et al. Rectal cancer patients with downstaging after neoadjuvant chemoradiotherapy and radical resection do \\ not benefit from adjuvant chemotherapy. Ann Transl Med 2020;8:743.
}

Submitted Jul 01, 2020. Accepted for publication Aug 16, 2020.

doi: $10.21037 /$ atm-20-5088

View this article at: http://dx.doi.org/10.21037/atm-20-5088

Surgery is the cornerstone to the cure of colorectal cancers. Resection techniques for rectal tumors have been substantially improved thanks to the knowledge of dissemination mechanisms, thereby increasing cure rates; however, the best oncological results for patients with locally advanced stages have been obtained by combining the use of chemotherapy and radiotherapy with the surgery. Once the primary treatment is completed, there is an open debate on whether to continue the adjuvant therapy, especially with patients who have downstaging. We read with great interest the work of Zhang et al. (1), where they evaluated the effect of adjuvant chemotherapy on the survival of patients with adenocarcinoma of the middle and lower rectum treated with preoperative chemoradiotherapy (NCRT) + radical resection of the rectum with negative margins in the pathological stage pT0- T2 N0. Based on their results, we can conclude that patients with NCRT stages 0 -II (excluding T3 and T4 tumor stages) cancers with complete resection who received adjuvant chemotherapy had a survival similar to those who did not receive it $(79.1 \%$ vs. $82.9 \%, \mathrm{P}=0.442)$, however, it must be considered that patients in the "non-adjuvance" group had a higher proportion of anastomosis leaks (19.3\% vs. $6.6 \%, \mathrm{P}=0.042)$ and were older $(61.2$ vs. 55.6 years, $\mathrm{P}=0.012$ ), factors that they seem to have a poor prognosis. The factor that was definitely associated with better diseasefree survival at 5 years was the administration of NCRT + chemotherapy (total NCRT), a fact that has been consistently shown to be associated with better oncological results (2), so it would provide clarity to Zhang's report to stratify for the use of total NCRT; however, given the low proportion of cases in the adjuvant group $(\mathrm{n}=30)$ this may not be possible. Also, although it is established that a total mesorectal excision (TME) was performed in the patients, the quality of TME is not established, and this is a very important information since its correlation with oncological outcomes is well known (3). We are interested in this issue, so we present an analysis of the use of adjuvant chemotherapy in our patients with stages II and III adenocarcinoma of the lower and middle rectum in the period from 2010 to 2017, with tumor stages pT3 and pT4 and who received NCRT 3-6 cycles of capecitabine or CapeOX + 50.4 Gy of radiotherapy (none patient received total NCRT). We find a total of 161 patients, with a median age of 58 years (range, 23-85 years) and, as can be seen in Table 1, the clinicopathologic characteristics known as

^ ORCID IDs: Leonardo S. Lino-Silva: 0000-0002-7394-5123; César Zepeda-Najar: 0000-0002-4913-7695; Rosa A. Salcedo-Hernández: 0000-0003-4537-8034. 
Table 1 Analysis of 161 patients with rectal adenocarcinoma treated with preoperative chemoradiotherapy + radical surgery divided according to adjuvant therapy use

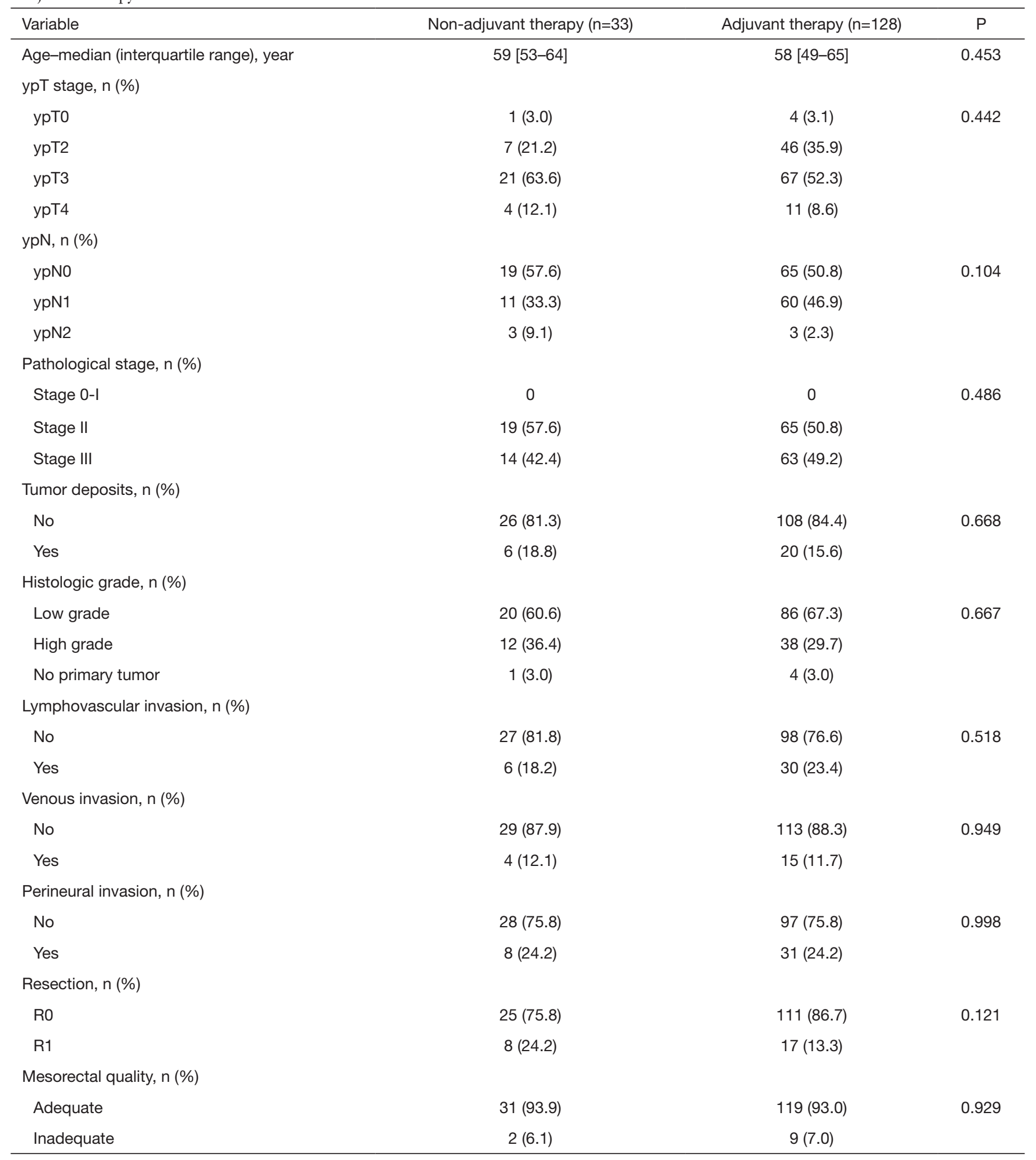

Table 1 (continued) 
Table 1 (continued)

\begin{tabular}{lcc}
\hline Variable & Non-adjuvant therapy $(\mathrm{n}=33)$ & Adjuvant therapy $(\mathrm{n}=128)$ \\
\hline $\begin{array}{l}\text { Number of resected lymph nodes, median } \\
\text { (interquartile range) }\end{array}$ & $13[10-17]$ & $13[10-16]$ \\
Outcome, $\mathrm{n}(\%)$ & & 0.764 \\
Alive without disease & $15(45.5)$ & $66(51.6)$ \\
Dead & $7(21.2)$ & $23(18.0)$ \\
Alive with disease & $7(21.2)$ & $34(26.6)$ \\
Dead without disease & $4(12.1)$ & $5(3.9)$ \\
Follow-up, median (interquartile range), months & $39[16-70]$ & $44[29-64]$ \\
\hline
\end{tabular}

${ }^{*}$, $\mathrm{P}$ values are based on Mann-Whitney $\mathrm{U}$ test for numerical variables and chi-square or Fisher exact test as appropriate; ${ }^{+}$, comparison between alive $v s$. dead results in a $P$ value of 0.170 .

factors associated with prognosis in this type of patients are completely balanced between the groups. Survival analysis with the Kaplan-Meier method shows that patients who did not receive adjuvant therapy had a disease-specific survival of 72.4 months compared to 75.3 months for those who received it $(\mathrm{P}=0.523$, log-rank test $)$ and an overall survival of 63.1 vs. 71.9 months $(\mathrm{P}=0.127, \log$-rank test $)$.

Our results confirm the findings found by Zhang (1), in another type of population and in a sample that predominantly received adjuvant treatment and that did not receive total NCRT. Furthermore, we found that there was no difference when considering early stages with pT34 tumors, neither lymph node disease nor tumor deposits. These findings establish the basis for developing a clinical trial in which this type of patient is randomized to receive or not adjuvant treatment in a standardized prospective cohort to settle this question at once.

\section{Acknowledgments}

Funding: None.

\section{Footnote}

Conflicts of Interest: All authors have completed the ICMJE uniform disclosure form (available at http://dx.doi. org/10.21037/atm-20-5088). The authors have no conflicts of interest to declare.

Ethical Statement: The authors are accountable for all aspects of the work in ensuring that questions related to the accuracy or integrity of any part of the work are appropriately investigated and resolved.

Open Access Statement: This is an Open Access article distributed in accordance with the Creative Commons Attribution-NonCommercial-NoDerivs 4.0 International License (CC BY-NC-ND 4.0), which permits the noncommercial replication and distribution of the article with the strict proviso that no changes or edits are made and the original work is properly cited (including links to both the formal publication through the relevant DOI and the license). See: https://creativecommons.org/licenses/by-nc-nd/4.0/.

\section{References}

1. Zhang H, Huang Y, Sun G, et al. Rectal cancer patients with downstaging after neoadjuvant chemoradiotherapy and radical resection do not benefit from adjuvant chemotherapy. Ann Transl Med 2020;8:743.

2. Petrelli F, Trevisan F, Cabiddu M, et al. Total Neoadjuvant Therapy in Rectal Cancer: A Systematic Review and Meta-analysis of Treatment Outcomes. Ann Surg 2020;271:440-8.

3. Silva-Velazco J, Stocchi L, Valente MA, et al. The relationship between mesorectal grading and oncological outcome in rectal adenocarcinoma. Colorectal Dis 2019;21:315-25.

Cite this article as: Lino-Silva LS, Zepeda-Najar C, SalcedoHernández RA. Adjuvant therapy in patients with rectal adenocarcinoma treated with neoadjuvant chemoradiotherapy and radical resection in pathological stages I-III. Ann Transl Med 2020;8(17):1116. doi: 10.21037/atm-20-5088 